\title{
Integrated Financial Management Information Systems: Guidelines for effective implementation by the public sector of South Africa
}

\author{
Author: \\ Christoffel J. Hendriks ${ }^{1}$ \\ Affiliation: \\ ${ }^{1}$ Department of Public \\ Administration and \\ Management, University of \\ the Free State, South Africa \\ Correspondence to: \\ Chris Hendriks \\ Email: \\ hendrikscj@ufs.ac.za \\ Postal address: \\ PO Box 339, Bloemfontein \\ 9300, South Africa \\ Dates: \\ Received: 22 June 2012 \\ Accepted: 01 Oct. 2012 \\ Published: 12 Dec. 2012 \\ How to cite this article: \\ Hendriks, C.J., 2012 \\ 'Integrated Financial \\ Management Information \\ Systems: Guidelines for \\ effective implementation \\ by the public sector of \\ South Africa', SA Journal of \\ Information Management \\ 14(1), Art. \#529, 9 pages. \\ http://dx.doi.org/10.4102/ \\ sajim.v14i1.529
}

(C) 2012. The Authors. Licensee: AOSIS OpenJournals. This work is licensed under the Creative Commons Attribution License.
Background: Integrated Financial Management Information Systems (IFMIS) can improve public sector management by providing real-time financial information to managers in order to enhance their decision-making capabilities. The South African Public Service is currently busy with the implementation of an IFMIS. However, the implementation of such a project has proved to be a very demanding undertaking and has not been met with resounding success.

Objectives: The research was conducted in order to identify the challenges and risks that are involved in the implementation of the IFMIS in South Africa. After identification of the challenges and risks, solutions or guidelines were developed that may make the implementation more successful.

Method: The methodology that was used is that of a literature study where theories were explored and used to solve a research problem. Based on the theoretical research, solutions and guidelines were developed to solve challenges and risks experienced.

Results: The results indicated that there are a number of challenges involved with the implementation of an IFMIS. A set of best practice guidelines was developed that may make the implementation more successful.

Conclusion: The sheer size and complexity of an IFMIS poses significant challenges and a number of risks to the implementation process. There are, however, critical success factors or best practices that can be used for the project to succeed. It is recommended that these best practices be used by the South African Public Service.

\section{Introduction}

Governments in developing countries are increasingly exploring methods and systems to modernise and improve public financial management. For example, over the years, there has been an introduction of the Integrated Financial Management Information System (IFMIS) as one of the most common financial management reform practices, aimed at the promotion of efficiency, effectiveness, accountability, transparency, security of data management and comprehensive financial reporting. The scope and functionality of an IFMIS varies across countries, but normally it represents an enormous, complex, strategic reform process (Chêne 2009:3).

The sheer size and complexity of an IFMIS poses significant challenges and a number of risks to the implementation process that goes far beyond the mere technological risk of failure and deficient functionality. The introduction of an IFMIS can be regarded as an organisational reform which deeply affects work processes and institutional arrangements governing the management of public finance. Challenges and obstacles can have a devastating effect on the success of the implementation and management of the process and should not be underestimated (RodinBrown 2008:2; Hove \& Wynne 2010:8).

Various factors determine the success of IFMIS development and implementation in developing countries. In this article the purpose is to identify some of the challenges and to present solutions that can serve as best practice guidelines in the implementation of an IFMIS. The research problem that this study aims to address is to identify the challenges relating to the implementation of an IFMIS and to present best practise guidelines that will facilitate a successful implementation of an IFMIS in the South African Public Sector. The methodology used is that of a literature study where theories are explored and used to solve a research problem. According to Cooper and Schindler (2006:719), theory is a set of systematically inter-related concepts, definitions and propositions that are advanced to explain or predict phenomena (facts). Good theories and models provide causal accounts of the world, allow one to make predictive claims under certain conditions, bring conceptual coherence to a domain of science and simplify our understanding of the world (Mouton 2001:177). 


\section{Definition of the concept}

According to both Dorotinsky (2003:3) and Rozner (2008:1), an IFMIS is an information system that tracks financial events and summarises financial information. It supports adequate management reporting, policy decisions, fiduciary responsibilities and the preparation of auditable financial statements. In its basic form, an IFMIS is little more than an accounting system configured to operate according to the needs and specifications of the environment in which it is installed (Rodin-Brown 2008:2). In general terms, it refers to the automating of financial operations.

In the sphere of government operations, IFMIS refers to the computerisation of public financial management processes, from budget preparation and execution to accounting and reporting, with the help of an integrated system for the purpose of financial management (Lianzuala \& Khawlhring 2008:1). Rodin-Brown (2008:2) identifies the following basic features that are necessary for integration:

- standard data classification for recording financial events

- internal controls over data entry, transaction processing and reporting

- common processes for similar transactions and a system design that eliminates unnecessary duplication of data entry.

According to the IFMIS Project Overview for South Africa (Van Deventer 2003:8), a corporate reference data (CRD) Management Module will provide for the features mentioned above.

\section{Characteristics, objectives and advantages of an Integrated Financial Management Information System}

According to Diamond and Khemani (2006:99) and Chêne (2009:2), a well-designed Integrated Financial Management Information System (IFMIS) contains the following characteristics: it is a management tool; it provides a wide range of non-financial and financial information; it is a system and it impacts on corruption.

\section{Management tool}

According to Hove and Wynne (2010:8), an IFMIS assists management in ensuring accountability for the deployment and use of public resources and in improving the effectiveness and efficiency of public expenditure programmes. By tracking financial events through an automated financial system, management is able to exercise improved control over expenditure and to improve transparency and accountability in the budget cycle as a whole. Diamond and Khemani (2006:99) argue further that, as a management tool, an IFMIS should support the management of change. As such, it should be viewed as part of the broader financial reforms of government, such as budget reforms.
As a management tool IFMIS also enables management to do the following (Barata \& Cain 2001:248):

- Control aggregate spending and the deficit.

- Prioritise expenditure across policies, programmes and projects to achieve efficiency and equity in the allocation of resources.

- Make better use of budgeted resources, namely, to achieve outcomes and produce outputs at the lowest possible cost.

\section{Provision of nonfinancial and financial information}

An IFMIS provides decision-makers and public-sector managers with the information they need to perform their managerial functions. Rodin-Brown (2008:3) states that an IFMIS provides timely, accurate and consistent data for management and budget decision-making. By computerising the budget management and accounting system for a government, an IFMIS aims at improving the quality and availability of information necessary at various stages of public financial management, such as budgeting, treasury management, accounting and auditing (Dorotinsky \& Matsuda 2001:3). An IFMIS allows users anywhere within the IFMIS network to access the system and extract the specific information they need. A variety of reports can be generated to address different budgeting, funding, treasury, cash flow, accounting, audit and day-to-day management concerns (Rozner 2008:1).

\section{A system}

The scope and functionality of an IFMIS can vary from a basic general ledger accounting application to a comprehensive system covering budgeting, accounts receivable or payable, cash management, commitment control, debt, assets and liability management, procurement and purchasing, revenue management, human resource management and payroll (Rozner 2008:1). Its role is to connect, accumulate, process and then provide information to all parties in the budget system on a continuous basis (Diamond \& Khemani 2006:100). It is therefore imperative that the system should be able to provide the required information timely and accurately, because if it does not it will not be used and cease to fulfil its central function as a system.

An IFMIS can improve public financial management in a number of ways, but generally seeks to enhance confidence and credibility of the budget through greater comprehensiveness and transparency of information. The purpose of using an IFMIS is to improve budget planning and execution by providing timely and accurate data for budget management and decision-making (Chêne 2009:2). A more standardised and realistic budget formulation process is allowed for and improved control over budget execution is affected through the full integration of budget execution data.

\section{Impact on corruption}

One of the major benefits of an IFMIS is the impact that it can have on corruption, by increasing the risk of detection. 
According to Chêne (2009:2), a well-designed IFMIS can provide a number of features that may help detect excessive payments, fraud and theft. These include, for example, automated identification of exceptions to normal operations, patterns of suspicious activities, automated cross-referencing of personal identification numbers for fraud, crossreferencing of asset inventories with equipment purchase to detect theft, automated cash disbursement rules and identification of ghost workers.

At the launch of the Human Resource (HR) module of the IFMIS in South Africa, the Minister of Public Service and Administration stated (Baloyi 2011):

The implementation of the module is critical for supporting good governance. Corruption remains the biggest single threat to good governance in South Africa and in the public service and fighting it remains a major challenge. Through implementing the HR module, government departments will be in a better position to eliminate ghost workers and the abuse of leave. The module will enable management to manage the disciplinary process in the Public Service better and will also automate the declaration of financial interests by senior managers. (p. 1)

\section{Background to the South African scenario}

According to Nomvalo (2008:8), IFMIS in South Africa forms part of the broader financial management reforms of the South African government, which started in 1994 with the institutionalisation of democracy in South Africa. The reform process was executed in four phases. The first phase (1994-1998) entailed the introduction of Medium-Term Expenditure Frameworks and a new classification system compatible with Government Financial Statistics (GFS).

In the second phase (1999-2002), the Accounting Standards Board and improved economic classifications were introduced in aid of effectively managing increased government expenditures. During the third phase (2003-2006), the government introduced a framework for Public Private Partnerships (PPP) and additional frameworks and policies were provided in areas such as Supply Chain Management (SCM). In addition, a risk management framework was also developed, whilst the latest phase began in 2007 with the commencement of the project for an IFMIS (Nomvalo 2008:8)

The IFMIS implementation project in South Africa is a priority initiative led by the National Treasury to review and upgrade the government's transverse information technology (IT) systems. The objective of this project is to enhance the integrity and effectiveness of expenditure management and performance reporting in order to ensure effective service delivery (National Treasury 2009:3). Transverse systems are defined as the general administrative systems required by all national departments and the provincial departments of all nine provinces, which include:

- financial management

- human resource management
- integrated supply chain management (including asset and procurement management)

- related business intelligence, audit and decision systems.

The South African government currently owns and operates a large compendium of systems in the transverse systems arena such as:

- the Financial Management System (FMS)

- the Basic Accounting System which is cash accounting systems

- the Personnel and Salaries Management System (PERSAL), which can be described as a payroll system

- the Logistical Information System(LOGIS), which supports the asset management and supply chain functions

- Vulindlela, a business intelligence system

- the Police Financial Management System (POLFIN), which is a department specific cash management system for the South African Police Services (O'Sullivan 2008:9).

As a whole these systems present a number of problems, such as:

- functional duplication and technological proliferation that has a negative impact on the cost-effective spending of public funds

- difficulties in the implementation of uniform norms and standards across systems and operations

- poor inherent systems of inter-operability and aggregating of data that seriously compromise operational integrity and the generation of management information

- difficulty in synchronising the implementation of new legislation and regulations with the capabilities of multiple systems, each on its independent evolutionary path (Van Deventer 2003:5).

According to $\mathrm{O}^{\prime}$ Sullivan (2008:9) the main reasons for the problems are the following:

- aging technologies are reaching the end of their life-span

- systems are fragmented and data integration is difficult

- economies of scale are not being realised

- new functional requirements arising from new legislation (such as the Public Finance Management Act or the Preferential Procurement Policy Framework Act) or new regulations (such as accrual accounting) are difficult to implement

- increasing support and maintenance costs of aging technologies

- inability to take advantage of new technologies such as web-services to extend the reach of service delivery

- inter-operability with other e-Government systems is difficult, if not impossible.

Thus, based on the above, one can assert that the longer this scenario continues, the more additional applications will be phased in and the more difficult it will become to rationalise government IT in South Africa.

In 2005, in order to give effect to the implementation of an IFMIS in South Africa, the South African cabinet approved a cabinet memo (resolution) that the transversal systems, namely, Supply Chain Management, Human Resources, Finance and Business Intelligence, should be replaced 
(National Treasury 2009:3). Thus, the IFMIS aims to replace the different transversal systems currently in use with a single system.

In 2007, the National Treasury informed the Standing Committee on Public Accounts that the IFMIS would be fully implemented by 2011. Different phases would be launched and early releases could be expected by 2008/2009 (Maake 2007:7). The implementation of an IFMIS in South Africa took place according to a phased-in approach as opposed to a onestage approach. Three distinctive implementation phases can be distinguished:

- Phase 1: Master Systems Plan - This phase culminated in a Master Systems Plan (MSP) detailing the project objectives and functional scope, which was presented to the Cabinet, which then authorised the project to proceed with Phase 2 in September 2005.

- Phase 2: Capacity and architecture - Phase 2 of the project focused on preparing the State Information Technology Agency (SITA) for its role as the Prime Systems Integrator (PSI). During this phase, a number of pressing user requirements was identified and the scope of Phase 2 was expanded to fast-track several Phase 3 deliverables. Two commercial, off-the-shelf (COTS) systems for Human Resource Management and Procurement Management were acquired and the development of an Asset Register was initiated. During Phase 2, SITA also acquired a suite of software to support an Integrated Development Environment (IDE) for the in-house development of the bespoke software components of the system, of which the Asset Register was the first.

- Phase 3: Development and implementation - Phase 3 entailed the development and procurement of the various systems components and their phased deployment. During this phase, detailed system specifications were developed for each functional requirement identified in the IFMIS Conceptual Architecture. Using these specifications, the IFMIS team built the software components and integrated them with the COTS software to provide a 'government offthe-shelf' system (colloquially called 'GOTS' by the team). The development of an IFMIS was done incrementally within a well-defined, modular framework. A risk-averse deployment strategy was developed whereby each piece of new functionality was implemented at a lead site to ensure that all functional requirements and end-user support structures were fully operational before the module was deployed nationally.

The team used Open Standards to guarantee inter-operability and made use of Free and Open Source Software (FOSS) wherever possible, unless proprietary software was shown to be significantly superior. This is in line with the Cabinet's policy on the use of Free and Open Source Software. It was expected to take approximately five to seven years to complete the development of an IFMIS (Maake 2007:5).

South Africa is currently implementing different modules of the IFMIS at lead sites in both the national and the provincial departments to ensure that all functional requirements are met (Govender 2012:1).

\section{Challenges involved in the implementation of an Integrated Financial Management Information System}

The sheer size and complexity of an Integrated Financial Management Information System (IFMIS) poses significant challenges and a number of risks to the implementation process that go far beyond the mere technological risk of failure and deficient functionality. Studies conducted in various countries such as Tanzania, Ghana, Uganda, Malawi, Kenya and Rwanda indicated that there are a number of challenges that may influence the successful implementation of an IFMIS (Diamond \& Khemani 2006:110; Rodin-Brown 2008:2). Some of the most common challenges that may be faced by developing countries are discussed in the subsections that follow. It is necessary for these challenges to be discussed in order to develop guidelines for better implementation of an IFMIS.

\section{Lack of capacity}

The effective implementation, operation and maintenance of an IFMIS require staff with the necessary knowledge and skills. Lack of capacity is regarded as one of the main causes for the delay in the implementation process experienced by Ghana, whilst the emphasis that was put on capacity building through training in Tanzania was one of the main contributors to their success. (Diamond \& Khemani 2006:112).

The lack of staff with IT knowledge and experience cannot be easily remedied by training and hiring. The salary structure and terms of employment in the public sector are usually not attractive enough to compete with the private sector and to incentivise candidates with the required IT-skills levels (Chêne 2009:4). Trained personnel also leave the government service, often for better job opportunities.

Brar (2010:55) argues that low capacity for system implementation at the sub-national level, such as provincial and regional governments, is one of the major challenges in the implementation of an IFMIS in developing countries. This aspect is especially relevant in the South African context with its nine provinces and the consequent demand that the duplication of efforts creates for skills and knowledge, of which a shortage already exists. Farelo and Morris (2006:11) contend that the human resource development issue within government needs prioritisation, the education system needs to be aligned with the information and communication technologies (ICT) demands of the country and scarce ICT skills need to be attracted and retained particularly within government.

\section{Weak commitment to change}

The implementation of an IFMIS is a complex, risky, resourceintensive process that requires major procedural changes and often involves high-level officials who lack incentives for reform (Chêne 2009:4). It demands a commitment to change: 
change in technology; in processes and procedures; as well as changes in skills, responsibilities and behaviours (RodinBrown 2008:29). Considering the nature and complexity of the project it is essential for all participants to be fully aware of the magnitude of the undertaking. Decision-makers must be convinced that the benefits of an IFMIS exceed the risks, and participating departments must recognise the need for a new system (Chêne 2009:4). According to Peterson (1998:43), the commitment of senior managers is one of the most frequently cited factors deciding the success or failure of an information system. Chêne (2009:6), however, argues that the Ethiopian case study has proven that what matters most in the process is mid-level management's commitment to reform, as the changes ultimately have to be implemented at this level. Diamond and Khemani (2006:105) argue that project commitment at the highest levels of the political system, as well as bureaucracy, and continuous participation from the direct users of the system and other stakeholders in all phases of the project, is necessary for success. Case studies of more successful countries, such as Kosovo, the Slovak Republic, Tanzania and Ethiopia, indicate that the clear commitment of the relevant authorities is one of the main factors supporting successful implementation of an IFMIS (Chêne 2009:4).

\section{Institutional challenges}

The introduction of an IFMIS involves more than only the automation of public finance tasks and processes. RodinBrown (2008:7) identifies a number of institutional issues that should be anticipated and planned. These issues include, amongst other organisational arrangements, the legal framework and business functional processes.

\section{Organisational arrangements}

Chêne (2009:3) asserts that an IFMIS implies both efficiency reforms and reforms that change existing procedures. It involves organisational reform, which deeply affects work processes and institutional arrangements governing the management of public finance. Institutional reform is, however, not easily achieved and, according to the International Consortium of Governmental Financial Management (ICGFM) (2008:166), it takes time, commitment, champions and courage to achieve.

Indeje and Zheng (2010:6) contend that the introduction of a new information system fundamentally changes the way operations are carried out and therefore requires a carefully managed process. This process results in the creation of a new organisational culture, that is, change in the way the organisation operates. In Rwanda, for example, there were three teams responsible for the development of the IFMIS. Lack or little co-ordination between the teams resulted in the IFMIS being incompatible with the system developed for the Rwanda Revenue Authority (Hove \& Wynne 2010:26).

\section{Legal framework}

An IFMIS must be underpinned by a coherent legal framework governing the overall public finance system
(Chêne 2009:3). Amongst other things there should be clear legal guidance on the roles and responsibilities of all institutions in managing, controlling, and monitoring budget execution; the authorisation, commitment and release of funds; the basis of accounting (cash or accrual); reporting requirements; and, asset management, public investment and borrowing (Rozner 2008:2). According to Chêne (2009:5), the implementation of IFMIS in Tanzania was distinguished by revising and developing an enabling legislation which contributed to the success of the system.

\section{Business processes re-engineering}

An IFMIS generally implies fundamental changes in operating procedures and should be preceded by a detailed functional analysis of processes, procedures, user profiles and requirements that the system will support (Chêne 2009:3). Key high-level government goals will only be achieved if the IFMIS solution supports a wide range of business processes that transcend functional, business, organisational and geographic boundaries. IFMIS design should, therefore, be preceded by detailed functional analysis that underpins current functional processes, procedures, user profiles and requirements that the new system will support (Rozner 2008:2). In Ghana the design and development of IFMIS was not satisfying, because of problems with the reporting functionality. This was because of a lack of clear specifications on the reporting requirements and approval from government on the design of various reports (Diamond \& Khemani 2006:130).

Business process re-engineering is a critical aspect of any IFMIS reform and requires a review of all systems, functional processes, methods, rules and regulations, legislation, banking arrangements and related processes (Rodin-Brown 2008:8). It will be necessary to establish new, standardised procedures throughout the government to formalise job descriptions and to improve arrangements and systems for internal and external control.

\section{Technical challenges}

Many IFMIS projects have failed because the basic system functionality was not clearly specified from the onset of the intervention. Chêne (2009:4) posits that an IFMIS must be carefully designed to meet the needs and functional requirements, including the accounting and financial management tasks the system should perform. Consideration must be given to the type of systems that will be implemented, for example, off-the-shelf (OTS) or custombuilt systems that fit the requirements of the specific country. An analysis of the different systems used by developing countries indicates that they make use of both off-the shelf systems as well as custom-built systems. For example, Ghana and Uganda opted for a system designed and developed to fit their specific requirements, whilst Tanzania, Malawi and Kenya opted for off-the shelf systems. It is important to note that a determining factor in the success of the implementation is not in the type of system, (i.e. off-the-shelf or custom-built) but rather in the complexity of the system. One of the reasons 
for the success of Tanzania's project is, for example, their decision to purchase a less complex, mid-range commercial package (Diamond \& Khemani 2006:112).

\section{South African specific challenges}

South Africa is at the moment busy with the implementation phase of its IFMIS and according to Maake (2012:2) the following are some of the challenges experienced:

- The IFMIS programme has proved to be more complex than what was originally envisaged.

- There was an initial lack of sufficient capacity in the State Information Technology Agency (SITA) as the Prime Systems Integrator (PSI) from the commencement of the project.

- The movement of some Phase 3 deliverables (acquisition and implementation of COTS products) to Phase 2 placed an additional burden on the IFMIS project.

- Misalignment between the HRM product procurement and the Payroll product development resulted in challenges relating to the duplicate capturing of data on IFMIS and PERSAL in the HRM lead sites.

- There was insufficient capacity at user departments to take on IFMIS modules, for example, inadequate ICT infrastructure, budgets and staff with sufficient functional capabilities.

Kotze (2012) argues that implementation of the IFMIS has the effect that existing knowledge and expertise that was created over a lengthy period of time no longer exists. Officials are not trained in the new systems, are uncertain regarding functional processes which may delay the implementation process and they make mistakes. The fear to make mistakes also leads to resistance towards IFMIS which may impact negatively on its successful implementation.

Furthermore, there are still challenges experienced related to the clarity of roles with the implementation of IFMIS in the provincial sphere where the Provincial Treasuries as important role players do not have clearly defined roles and responsibilities (Kotze 2012). The absence of detailed implementation plans at lower levels, where the IFMIS is actually implemented, also influences the implementation process negatively (Kotze 2012).

\section{Guidelines for successful implementation of an Integrated Financial Management Information System}

The requirements for the introduction of an Integrated Financial Management Information System (IFMIS) may differ from country to country, but there are critical success factors or best practices that are important for the project to succeed. The best practices include the following.

\section{Change management}

Change management can be described as the creation, maintaining and systematic evaluation of changes in an organisation (Barcan 2010:93). It aims at maximising an organisation's ability to achieve success through involved, educated and committed people. O'Sullivan (2008:40) asserts that change management includes a stakeholder management model, a communication strategy, a change-readiness assessment framework and certain design elements.

The management of the changes that accompany the implementation of an IFMIS can be regarded as one of the most critical, but also one of the most neglected aspects of IFMIS reforms. The success of IT reforms depends upon the capacity of the organisation to change, to manage the change and to survive whilst changing (Peterson 1998:38). Resistance to change may come from various stakeholders in the organisation, such as individuals with vested interests who benefited from previous methods, civil servants who see it as a threat to their jobs and people who resist change simply for fear of the unknown.

According to Rozner (2008:3), a change management strategy should be developed as soon as an IFMIS project is conceived, taking into consideration the change implications for diverse stakeholders, that is, from politicians and senior officials to heads of departments, civil servants and the IT personnel who will support the new systems. If this aspect is not addressed early in the project, the project will constantly be faced with resistance and obstacles from elected politicians, executive officials and personnel who will use the systems regularly.

The best way to overcome resistance to change will be through clear communication, education and training, as well as through 'quick wins' that demonstrate the benefits of the change (Rozner 2008:4). The communication can be done through a variety of media, workshops, seminars, training sessions, a website, conferences, or newsletters (RodinBrown 2008:24).

\section{Ensuring project commitment}

Various writers such as Peterson (1998:43), Chêne (2009:6) as well as Diamond and Khemani (2006:105) argue that the importance of commitment by politicians and management is vital to ensure success of the implementation of an IFMIS. Experience indicates that the best designed project will fail without firm commitment from all stakeholders involved, including politicians, as well as senior and middle management. Thus, Diamond and Khemani (2006:105) posit that ensuring project commitment at the highest levels of the political system and of management and continuous participation from the direct users of the system is necessary in all phases of the project.

In South Africa, political commitment was obtained through a cabinet resolution when Cabinet approved the IFMIS project in 2005. The President of the Republic of South Africa has also committed South Africa not only to participate, but also to compete internationally in the Information Society (Farelo \& Morris 2006:7). For this purpose, the Presidential National 
Commission on Information Society and Development (PNC on ISAD) was established in 2001 by the President of the Republic of South Africa to advise and to co-ordinate ICT initiatives broadly. The PNC on ISAD works closely together with the Minister of Communications on ICT strategies for the Information Society as a whole. Co-ordination of e-government, as well as the governance of ICTs within the government, is the responsibility of the Minister of Public Service and Administration, who is tasked with this process (Farelo \& Morris 2006:7). Whilst political commitment may exist at the national political level, political commitment in the provincial sphere and commitment from officials at all levels involved must be ensured for success.

\section{Creating a legal framework}

It is important to have clear legal guidance on the roles and responsibilities of all institutions involved in the implementation of an IFMIS. According to Diamond and Khemani (2006:110), a legislative framework consists of the constitution, finance act and regulations, and needs to include:

- the roles and responsibilities of the treasury, and other departments responsible for the control and management of public finance

- the main form of government funds, receipt and custody of public funds, the annual process, submission and approval of estimates and the procedures for release of funds

- the basis of accounting and the form of annual accounts for audit and presentation to Parliament

- asset management and control, borrowing and investment.

Legal reforms, however, are seldom simple or swift, but this process need not obstruct IFMIS implementation (Rozner 2008:2).

In South Africa, the legislative framework for implementation of an IFMIS is enshrined in the Constitution of the Republic of South Africa (Republic of South Africa 1996) and the Public Finance Management Act (Republic of South Africa 1999). The Constitution confers extensive powers on the national government to determine the financial management framework over all organs of state, in all spheres of government. The National Government must, through national legislation, establish a national treasury and prescribe measures to ensure transparency and expenditure control in each sphere of government by introducing generally recognised accounting practices, uniform expenditure classifications, and uniform treasury norms and standards.

The Public Finance Management Act (Republic of South Africa 1999) which gives effect to the Constitution has the following key objectives:

- to modernise the system of financial management in the public sector

- to enable public sector managers to manage, but at the same time be held more accountable

- to ensure the timely provision of quality information

- to eliminate waste and corruption in the use of public assets.
The Act is part of a broader strategy on improving financial management in the public sector through various reform projects and strategies, such as budget and procurement reforms introduced by the first South African democratic government.

\section{Solving technical challenges}

IFMIS projects often fail because the basic system does not meet the requirements and tasks it should perform (Chêne 2009:4). The main aim of an IFMIS is to integrate all aspects of the government's budgetary cycle and provide suitable interfaces to other systems and entities. Barata and Cain (2001:247) posit that a technical appraisal of the IFMIS should identify the strengths and weaknesses of the system, taking into account the full picture of what the system is required to achieve.

In South Africa, this problem is dealt with by ensuring that the IFMIS Data Architecture is required to meet challenges posed by the sheer size and complexity of the system when considering the number of business domains included (finance, SCM, Human Resource Management and business intelligence). The mixture of COTS and bespoke developed subsystems interfaces with departmental core systems, with systems of business partners, with legacy systems during the lengthy phase-out period, and with constantly changing and diverging business requirements (O'Sullivan 2008:30).

\section{Capacity building and training}

Capacity building is a major factor affecting the success of IFMIS implementation, especially in developing countries (Chêne 2009:9). An IFMIS comprises more than only implementing a project; it also means planning for capacity building. A comprehensive training programme is therefore vital for the success of the project and should be compiled as early as possible. Training is essential to unlocking client readiness and is the best way to ensure sustainability of a system (Vickland \& Nieuwenhuijs 2005:101).

According to Maake (2007:7), the challenges that South Africa faces include access to appropriate IT skills as well as appropriate functional skills by user departments. South Africa faces significant human capital development challenges in building the capacity required by an IFMIS. The shortage of skilled ICT people in the country is exacerbated by the emigration of highly skilled ICT personnel and other professionals to developed countries, and from the public to the private sector (Farelo \& Morris 2006:6).

In order to build the necessary capacity, it is important to create a learning environment early in the project and to treat the whole process as a learning opportunity with training being part of an ongoing process. Training should be provided to senior managers, technical staff and end users, and should teach users how to use the new system and how it affects business processes. Diamond and Khemani (2006:108), however, argue that the training will not only 
include training in the use of the IFMIS for the respective operations and functions, but will also entail training in the new legal and regulatory framework, the new codes and classifications, and the new business procedures put in place.

A well-defined training programme will also assist in building capacity and help build confidence amongst users who, through the process, are reassured that there will be some constants amidst the change. Given the nature of institutions and organisations, capacity building is a neverending process. It needs to be ongoing and permanent (Rodin-Brown 2008:24).

\section{A phased approach to Integrated Financial Management Information System implementation}

The implementation of an Integrated Financial Management Information System (IFMIS) is a comprehensive process that requires patience. The full project's life cycle, from the definition of objectives, to system specifications, to system procurement, configuration, testing, pilot installation and rollout, can take years to complete (Rozner 2008:4). According to Rodin-Brown (2008:1X), a phased approach offers the best chances for successful implementation of an IFMIS, as a project can be carefully monitored and reviewed regularly. There are high risks involved in implementing too many components of the system at once and to mitigate the risk it is recommended that a phased approach be followed that rolls out across government institutions in a gradual and flexible process.

Procurement specifications for an IFMIS are not as clearly definable as, for example, the specifications for a vehicle or stationery, which can be defined with clear specifications. An IFMIS seems to be definable, but in reality there are too many interdependent variables that need to be firmed up as the process of implementation evolves (Rodin-Brown 2008:14). By following a phased approach, the project can be separated into smaller manageable units that can allow for 'quick wins' that help sustain or renew commitment from all involved. As each phase is completed, stakeholders can carefully assess project progress and make the necessary adjustments.

South Africa, being in the fortunate position to benefit from recent experiences in other countries, followed a phased approach towards an IFMIS with Phase 1 being the development of a Master Systems Plan, Phase 2, Capacitating and Architecture, and Phase 3, Development and Implementation. At the moment, different modules are being tested for deployment at pilot departments, both nationally and provincially.

\section{Project management and oversight}

When implementing an IFMIS, strong project management is critical for the success of the initiative (Vickland \& Nieuwenhuijs 2005:101). Project management entails more than managing the technical aspects of implementation. It also involves project planning methodologies to plan, implement and monitor the project, with project management responsibilities clearly identified.

An adequate project implementation team should therefore be established, ideally comprising a project manager, a public finance economist, a qualified accountant, a change management or training specialist, an IT-system specialist and a logistics specialist (Chêne 2009:8). At the same time, the programme manager must have the necessary managerial and leadership skills to direct and co-ordinate diverse activities executed by a wide range of specialists. The team should strive to adhere to the project implementation plan, but there should be flexibility to address inevitable changes, with approval through a programme governance structure.

In order to fulfil this role, the National Treasury in South Africa has set up a dedicated IFMIS project office composed of the following specialist functions: project management, systems engineering, domain specialists and information technology (Van Deventer 2003:12). The Programme Management Office (PMO) works with the IFMIS Programme Managers to monitor the execution of the project schedule and the budget. It is responsible for the development and implementation of policies and processes for the project. Project planning in the PMO is guided by the Project Management Body of Knowledge (PMBOK) framework and uses detailed project planning procedures derived from the Projects in Controlled Environments (PRINCE2) project management method. According to O'Sullivan (2008:11), the focus of this methodology is on the production of specific deliverables which ensure that planning and execution are based on measurable outputs that deliver strategic value.

\section{Project implementation plan}

The project implementation plan should cover immediate, medium-term and long-term IFMIS tasks and objectives, whilst a clear mission statement will help control the project direction, participant expectations and, ultimately, project costs. Rozner (2008:4) recommends that it should clearly define parameters, including the system objective and scope, the overall system conceptual design, expected impact and benefits, critical milestones and success factors, project implementation methodology, risk assessment or mitigation strategy, estimated costs and the financing arrangements.

Because the time span involving the implementation of an IFMIS is so long, it is inevitable that governmental changes, which often lead to structural changes, will occur. The project management implementation plan should therefore be revisited regularly to ensure that the situation has not changed substantially.

The South African IFMIS project implementation plan is derived directly from the IFMIS architecture effort. The principles adopted and the reference models developed from the MSP and the user-requirement specifications (URS) gave rise to the functional and technical architectures (O'Sullivan 2008:38). 


\section{Conclusion}

IFMISs form part of the financial management reform practices of developing countries globally. It holds benefits such as effective control over public finances, contributes to the enhancement of transparency and accountability and serves as a deterrent to corruption and fraud.

The study has shown that difficulties can be experienced with the implementation of an IFMIS. It will thus not always achieve the desired functionality and impact on public financial management that was originally anticipated. Obstacles such as a lack of capacity, a lack of commitment, and institutional and technical challenges pose a risk to the successful implementation of an IFMIS.

It is thus important that best practice guidelines be followed when the public sector implement an IFMIS. Such a decision needs to be accompanied by a capacity-building programme, the obtaining of commitment of all role players, the creation of a legal framework, an agenda for effective change management, a strong project management team, a phased approach to implementation and a well-defined project implementation plan. South Africa had the benefit of learning from experiences in other developed as well as developing countries. An IFMIS is now being implemented and is in its testing phase and follow-up studies should be conducted at a later time to determine the benefits achieved.

\section{Acknowledgements Competing interests}

The author declares that he has no financial or personal relationship(s) which may have inappropriately influenced him in writing this paper.

\section{References}

Baloyi, M.R., 2011, 'Address by the Minister for Public Service and Administration, Mr Masenyani Richard Baloyi, at the Integrated Financial Management System (IFMS) Human Resource (HR) go live celebration Pretoria Zoological Gardens', viewed 10 April 2011, from http://www.info.gov.za/speech/DynamicAction?pageid=461\& sid $=17409 \&$ tid $=3100$

Barata, K. \& Cain, P., 2001, 'Information, not technology, is essential to accountability Electronic records and public-sector financial management', The Information Society 17, 247-258. http://dx.doi.org/10.1080/019722401753330841

Barcan, L., 2010, 'New concepts in the change management within public organizations', Young Economists Journal Revista Tinerilor Economisti 8(14), 9397.

Brar, P., 2010, IFMIS in Africa: Some key issues, viewed 11 April 2011, from http:// www.eastafritac.org/images/uploads/documents_storage/IFMIS_Workshop Day_1_Presentations.pdf

Chêne, M., 2009, The Implementation of Integrated Financial Information Management Systems (IFMS), viewed 06 April 2011, from http://www.u4.no/ helpdesk/helpdesk/query.cfm?id=196
Cooper, D.R. \& Schindler, P.S., 2006, Business Research Methods, 9th edn., McGraw Hill, Boston.

Diamond, J. \& Khemani, P., 2006, 'Introducing financial management information systems in developing countries', OECD Journal on Budgeting 5(3), 97-132. http:// dx.doi.org/10.1787/budget-v5-art20-en

Dorotinsky, B., 2003, Implementing financial management information system projects: The World Bank experience, viewed 06 April 2011, from http://blog-pfm. imf.org/AIST2/Dorotinsky.ppt

Dorotinsky, W. \& Matsuda, Y., 2001, Financial management reform in Latin America: An institutional perspective, viewed 06 April 2011, from http://www.gsdrc.org/ docs/open/ PF32.pdf

Farelo, M. \& Morris, C., 2006, The Status of e-government in South Africa, viewed 11 April 2011, from http://hdl.handle.net/10204/966

Govender, K., 2012, Integrated financial management system and Persal projects. Departmental presentation, viewed 26 July 2012, from http://www.pmg.org.za/ report/

Hove, M. \& Wynne, A., 2010, The experience of medium term expenditure framework \& integrated financial management information system reforms in sub-Saharan Africa: What is the balance sheet?, viewed 07 April 2011 from http://www.acbfpact.org/knowledge/documents/Occasional_Paper 9.pdf

Indeje W.G. \& Zheng Q., 2010, 'Organizational culture and information systems implementation: A structuration theory perspective', Sprouts: Working Papers on Information Systems 10(27), viewed 12 April 2012 from http://sprouts.aisnet. org/10-27.

International Consortium of Governmental Financial Management (ICGFM), 2008 'Use of Financial Management Information Systems (FMIS) to improve financia management and accountability in the public sector', in International Journal on Governmental Financial Management, viewed 12 April 2012, from http://www. Governmental Finacial Mansilom: to-Improve-Financial-Management-and-Accountability-in-the-Public-Sector

Kotze, J.J., 2012, e-mail, 25 September, kobus@treasury.fs.gov.za

Lianzuala, A. \& Khawlhring, E., 2008, Mizoram IFMIS Project, viewed 06 April 2012, from http://www.docstoc.com/docs/39661608/Mizoram-IFMIS-Project

Maake, B., 2007, Presentation to National Treasury/Scopa Quarterly Meeting: Integrated Financial Management Systems (IFMS), viewed 09 April 2012 from http://www.pmg.org.za/docs/2007/ 070523ifms.ppt

Maake, B., 2012, IFMS presentation to the CFO Forum, viewed 20 September 2012 from http://oag.treasury.gov.za

Mouton, J., 2001, How to succeed in your masters and doctoral studies: a South African guide and resource book, van Schaik Publishers, Pretoria.

National Treasury, 2009, e-Procurement in South Africa, viewed 07 April 2012, from http://idbdocs.iadb.org/ wsdocs/getdocument.aspx?docnum $=2258376$

Nomvalo, F., 2008, Case study PFM reforms, A South African perspective, viewed 07 April 2011 from http://icgfm.blogspot.com/2008/12/case-study-pfm-reformssouth-african.html

O'Sullivan, G.S., 2008, IFMS Architecture Executive Overview, viewed 14 April 2012, from http://www.treasury.gov.za/ifms/secure/architecture.aspx

Peterson, S.B., 1998, 'Saints, demons, wizards and systems: why information technology reforms fail or underperform in public bureaucracies in Africa', technology reforms fail or underperform in public bureaucracies in Africa',
Public Administration and Development 18,37-60. http://dx.doi.org/10.1002/ Public Administration and Development 18, 37-60. http://dx
(SICI)1099-162X(199802)18:1<37::AID-PAD990>3.0.CO;2-V

Republic of South Africa, 1996, Constitution of the Republic of South Africa, 1996 (No. 108 of 1996), Government Printer, Pretoria.

Republic of South Africa, 1999, Public Finance Management Act, 1999 (No. 29 of 1999), Government Printer, Pretoria.

Rodin-Brown, E., 2008, Integrated Financial Management Information Systems: A practical guide, viewed 06 April 2011, from http://pdf.usaid.gov/pdf docs/ PNADK595.pdf

Rozner, S., 2008, Best practices in fiscal reform and economic governance. Introducing integrated financial management information systems, viewed 06 April 2011 from http://blog-pfm.imf.org/pfmblog/files/ifmis_bpn_web1.pdf

Van Deventer, L., 2003, Integrated Financial Management Systems (IFMS) Project Overview, viewed 16 April 2011, from http://www.treasury.gov.za/ifms/secure/ default.aspx

Vickland, S \& Nieuwenhuijs, I., 2005, 'Critical success factors for modernising public financial management information systems in Bosnia and Herzegovina', Public Administration and Development 25, 95-103. http://dx.doi.org/10.1002/pad.354 